Hutsol Kyrylo Development of diagnostic tools for determining levels of personality's narrative competence formation. European Journal of Education and Applied Psychology Scientific journal. 2020. № 1. ISSN 2310-5704.

URL: http://ppublishing.org/upload/iblock/e9d/Psychology 1-2020.pdf

Kyrylo Hutsol,

Post-graduate student, G. S. Kostiyk Institute of Psychology of the National Academy of the NAPS of Ukraine

https://doi.org/10.29013/EJEAP-20-1-31-34

\title{
DEVELOPMENT OF DIAGNOSTIC TOOLS FOR DETERMINING LEVELS OF PERSONALITY'S NARRATIVE COMPETENCE FORMATION
}

\begin{abstract}
The study concerned elaboration and testing of methodological tools for determining the development levels of narrative competence. These texts structurally consisted of three stages: selection of necessary narrative material for processing; development of diagnostic tasks for selected texts of narratives including criteria of formation of personality's narrative competence and algorithm for determining certain level of personality's narrative competence formation; involvement of a panel of experts to access the levels of respondents' narrative competence.
\end{abstract}

Keywords: narrative competence, pre-semantic, semantic, meta-semantic levels of narrative competence formation, formation criteria of narrative competence.

Problem statement. Of all discursive-oriented concepts of identity shaping, the narrative competence can consider its development and transformation to the fullest extent (M. Pasupathi [5], J. Vassilieva [6], J. Baddeley [1], J.A. Singer [1], J Brockmeier [3], D. Carbaugh [3]). In this context, narrative competence is viewed as a means of self-understanding and self-representation by which an individual self-designs and comprehends himself, his personal experiences, personal position, and the future. ( J.J. Bauer [2], S. Bluck [4], T. Habermas [4], D.P. McAdams [2], K.C. McLean [5]). However, the topic of narrative competence of personality remains under-researched in modern psychology, and there is a need for elaborating methodological tools concerning the formation criteria of narrative competence.

Purpose and methods. The study aims to develop and elaborate methodological tools to determine the development levels of narrative competence. The study applies an authorial methodology that involves the development of diagnostic tasks with selected narrative texts and an algorithm for determining the level of formation of narrative competence in the respondent. Results. The author chose a sample of 150 respondents aged 18 to 57 to conduct the empirical study. Respondents had to complete 14 tasks for each of the three proposed literary texts.

Questionnaire and method for processing the results 
1.How many parts do you think the text contains? Highlight them in the text.

0 - no answer; 1 - parts of the text are not correctly separated; 2 - parts of the text are correctly highlighted. 2. Make a detailed plan of the text. $0-$ no answer; 1 - the plan is not clearly structured; 2 - the plan is clearly structured. 3 . Make 3-5 questions to the text. 0 - no questions or questions are incorrect (irrelevant to the content of the text); 1 - questions to the text are within the content of the text; 2 - text questions go beyond the content of the text. 4 . Does the text present a problematic situation that the author seeks to resolve, what do you think is its intent? 0 - no answer or problem situation is featured incorrectly ("not in intent"); 1 - the problematic situation is presented, but it has a generalized character ( "non-personal"); 2-the problem situation is featured, and the respondent's personal involvement is observed. 5. Formulate the main idea of the text and summarize its contents in one sentence. 0 - no answer or the main idea of the text is featured incorrectly ( "not in intent"); 1-the main idea of the text is featured, but it has a generalized character ( "non-personal"); 2-the main idea of the text is featured, and the respondent's personal involvement is observed. 6 . Write a continuation of the text and include your assumption about the further development of the content (1-5 sentences). 0-no narrative continuation; 1-a narrative continuation is written, and it does not contain reflective information; $2-$ a narrative continuation is written, and it contains reflective information. 7 . Complete the sentence by reading the text, a)I was in complete agreement with the fact that... b) I was surprised to learn that... c) I was thinking on... d) If I would recommend reading this text, I would, first of all, emphasize on...

Each point of this task is evaluated separately: 0 - no answer or the answer is incorrect ( "not in intent");

1-the answer matches the content of the text; 2-the answer goes beyond the content of the text. 8. What do you think motivated the author to write this text? 0 - no answer or the answer is incorrect ( "not in intent"); 1 - the answer is generalized ("non-personal"); 2 - the respondent's personal involvement is observed. 9. Imagine that the author dedicated this text for you. Write your response to the author (1-3 sentences). 0-no response or the response is incorrect ( "not in intent"); 1 - the response has a generalized character ( "non-personal", without reflection); 2 - the response contains reflective information. 10. Ask 3-5 of your questions to the author of the text. $0-$ no answer or the answer is incorrect ( "not in intent"); 1-the answer within the content of the text; 2 -the answer goes beyond the content of the text. 11 . How useful was the text to you? $0-$ no answer or the answer is incorrect ( "not in intent"); 1 - the answer has a generalized character ("non-personal," without reflection); 2-the answer contains reflective information. 12. Who do you think would benefit from reading this text? 0 - no answer or the answer is incorrect ( "not in intent"); 1 - the answer has a generalized character ( "non-personal," without reflection); 2-the answer contains reflective information. 13. In your opinion, is there any idea that can be connected to these texts? 0 - no answer or no suggestions; 1 - the answer includes the idea, but the answer is not comprehensive; 2 - the answer includes the idea, the answer is comprehensive. 14. What difficulties did you experience in completing the 
tasks? 0 - no answer; 1 - the answer is not complete; 2 - expanded response. The key to determining the levels of respondents' narrative competence: pre-semantic level (tasks: 1, 2, 3); semantic level (tasks: 4, 5, 6, 7a, 7b, 7c, 10); meta-semantic level (tasks: 7d, 8, 9, 11, 12, 13, 14).

Identification of respondents who have a pre-conceptual level of narrative competence. The procedure considers the calculation of the sum of the points obtained from the questionnaire. The data processing suggests the following definition of hypothetical levels of pre-semantic level of formation of narrative competence: low- 0-6 points; average - 7-12; high-13-18. Frequency distribution of respondents with the pre-semantic level of narrative competence formation by sublevels out of 150 respondents: the low sublevel level of pre-semantic level of narrative competence has $3.3 \%$ (5 respondents); average - 20\% (30 respondents); high $-76.7 \%$ (115 respondents). The results defined the high level of pre-sense level of narrative competence formation of the respondents that can be both transitional from the presemantic level to the semantic level, and a higher level of their narrative competence formation: semantic or meta-semantic. The low and average levels of the pre-semantic level of the narrative competence of the respondents characterize the level of their formation that is no higher than the presemantic-level. Therefore, the pre-conceptual level was observed in $23.3 \%$ of the respondents; the level of formation of narrative competence of $76.7 \%$ of the respondents has to be identified.

Identification of respondents who have a semantic level of narrative competence. The first three subparagraphs of Task 7 (7a, 7b, 7c) determine and interpret the obtained results by calculating a total score, which is a mathematical expectation (arithmetic mean) of the rankings of these three responses to the selected texts. Thus, the maximum score is " 2 ". The distribution of hypothetically determined sublevels of the semantic level: low - 0-10; average - 10,01-20; high - 20,01-30. Frequency distribution of respondents with pre-semantic level of narrative competence formation by sublevels: $11.3 \%$ (13 respondents) of the 115 sublevels of semantic level of narrative competence formation; the average $49.6 \%$ (57 respondents); high $-39.1 \%$ (45 people). The low level of the narrative competence of the respondents indicates the transitional state of its formation from the pre-semantic level to the semantic level (13 respondents). The average sublevel of the semantic level of narrative competence indicates exactly this semantic level of narrative competence (57 respondents). The high level of semantic of respondents' narrative competence can be transitional from the semantic to the meta-semantic level of narrative competence, as well as the meta-semantic level. Therefore, the level of formation of the narrative competence in 45 respondents has to be identified.

Identification of respondents with a meta-semantic level of narrative competence. A score of 45 respondents was obtained for answering questions $7 \mathrm{~d}$, $8,9,11,12,13,14$. Distribution of hypothetically determined sublevels of metasemantic level: low - 0-14; the average-15-28; high-29-42. Frequency distribution of respondents with the meta-semantic level of narrative competence formation by sublevels: $26.7 \%$ (12 persons) of the low sublevel of the meta- 
semantic level of narrative competence formation. the average - 33.3\% (15 respondents); high $-40.0 \%$ (18 respondents). The defined low sublevel of the meta-semantic level indicates the transitional state of its formation from the semantic to the metasemantic level (12 respondents). Average and high metasemantic level sublevels correspond to the meta-semantic level of narrative competence formation (43 respondents).

The project involved 15 experts in defining the semantic levels of the respondents who completed 150 tasks in texts at the final stage of research. Therefore, all 450 tasks were processed by five experts. The experts were invited to analyze and determine the levels of formation of the respondents' narrative competence based on the proposed criteria. Criteria for the formation of the narrative competence of the individual at the pre-semantic level consider the ability to distinguish elements and components of the text, identify specific situations in text's statements, summarize the content of the text, develop an outline for the text, and ask questions about the content; at the semantic level, the criteria considers the ability to define the theme of the text (subject, intent), formulate the main idea, highlight the problem, make assumptions about the plot development, formulate questions to the author; at the meta-semantic level, criteria considers the ability to assume what exactly inspired the author to write the work, interpret and reflect ideas, assume the effect of getting acquainted with a text, and analyze the difficulties encountered in understanding the text. The proposed method of calculating the scores proved the reliability of determining the levels of respondents' narrative competence. This approach used correlative nonparametric analysis by Spearman's rank coefficient to determine the respondents' levels of narrative competence. Results proved a strong relationship $(\rho 0=0.97)$ at a high correlation index $(\mathrm{p} \leq 0.001)$.

Conclusions. The introduced author's methodology can be recommended for further studies and psychological practice as an efficient tool for determining the levels of formation of the narrative competence of the individual. Further research and related studies will focus on the development of psychological tools for identifying personality formation in the context of individual ability to selfdesigning.

References: 1. Baddeley J. \& Singer J.A. Charting the life story's path: Narrative identity across the life span. In J. Clandinin (Ed.), Handbook of narrative research methods Thousand Oaks, CA: Sage. 2007.- P. 177-202. 2. Bauer J.J. \& McAdams D.P. Personal growth in adults' stories of life transitions. Journal of Personality, 72, 2004.- P. 573-602. 3. Brockmeier J. \& Carbaugh D. (Eds.). Narrative and identity: studies in autobiography, self, and culture. - Amsterdam: John Benjamins, 2001.- P. 39-58. 4. Habermas T. \& Bluck S. Getting a life: The emergence of the life story in adolescence. Psychological Bulletin, 126(5), 2000.P. 748-769. 5. McLean K.C., Pasupathi M. \& Pals J.L. Selves creating stories creating selves: A process model of selfdevelopment. Personality and Social Psychology Review, 11, 2007.- P. 262-278. 6. Vassilieva J. Narrative psychology: identity, transformation and ethics. - London: Palgrave Macmillan. 2016. 